\title{
Expression of Cre Recombinase in Alveolar Epithelial Cells of the AQP2-Cre Transgenic Mini-Pigs
}

\author{
Weiwei Luo a,b,c Zhanjun Lia Peng Li ${ }^{a}$ Yongye Huang ${ }^{a}$ Yang Han ${ }^{a}$ Chaogang Yao ${ }^{a}$ \\ Zhongzhan Zhang ${ }^{d}$ Honggang Yane Daxin Pang ${ }^{a}$ Hongsheng Ouyang ${ }^{a}$ Li Lia $^{a}$ \\ ${ }^{a}$ College of Animal Science, Jilin University, ${ }^{b}$ State Key Laboratory for Molecular Biology of Special \\ Economic Animals, Institute of Wild Economic Animals and Plants, Chinese Academy of Agricultural \\ Sciences, djilin Animal Disease Control Center, eJilin Province Animal Health Inspection Institute, \\ Changchun, China
}

\section{Key Words}

Cre recombinase - Aquaporin 2 - Alveolar epithelial cells - Lung-specific expression • Conditional gene targeting

\begin{abstract}
Background/Aims: Optimal use of Cre mediated recombination in conditional animal models depends on well characterized Cre driver lines. Unfortunately, some Cre driver lines exhibit unexpected expression patterns hindering their utility in Cre/loxP systems. Thus, systematic assessment of new Cre lines is essential for generating useful Cre driver lines for future studies. Methods: Here, we describe a Cre Transgenic ( $\mathrm{Tg}$ ) mini-pig line in which the expression of Cre is directed by a 3-kb 5' fragment of the kidney-specific aquaporin 2 (AQP2); however, the AQP2-Cre Tg mini-pig line exhibits expression of Cre in alveolar epithelial cells (AECs) instead of collecting duct cells. The specificity of the AQP2-Cre plasmid was validated in vitro, and indicating that the AQP2-Cre was specifically expressed in the transfected LLC-PK1 cells. Absolute quantitative real-time PCR (qRT-PCR) and inverse PCR were performed to determine the copy numbers and integration sites of the AQP2-Cre transgene. Relative qRT-PCR was performed to evaluate variation in Cre expression levels over time. Results: Our data indicated that this AQP2-Cre Tg mini-pig line exhibits stable expression of Cre recombinase over time and in subsequent generations, even though the AQP2-Cre transgene was segregated and reduced in subsequent generations. Conclusion: Combined with our previous studies of the activity of this Cre, we conclude that this Cre Tg mini-pig line will provide a reliable tool for generating lung-specific gene targeting mini-pig models, thereby allowing the investigation of gene functions in lung development and studying the molecular mechanisms of human lung disease.
\end{abstract}

Copyright $@ 2014$ S. Karger AG, Basel

W. Luo and Z. Li contributed equally to this work. 


\section{Introduction}

The Cre/LoxP system is the most widely used conditional gene targeting strategy for spatial and temporal deletion of genes. This strategy exhibits a number of advantages compared with conventional gene targeting methods [1,2]. It can be used to mutate target sites at precise positions or in specific development stages. The conditional animals also avoid potential consequences due to complete gene inaction, such as developmental defects and systemic phenotypes. In addition, this system is simple and efficient, without the need of additional cofactors or sequence elements. Thus, the Cre/loxP recombination system is widely used in yeast [3], mammalian cells [4], and plants [5].

The utility of recombination in Cre/LoxP animal models is based on the availability of well-characterized Cre driver lines. By controlling the expression of Cre recombinase within a particular type of cell or at a specific development stage, it is possible to control gene deletion in corresponding cells or stages in animal models [6, 7]. Advances in mouse embryology and molecular genetics, have allowed for the generation of various kinds of Cre recombinase expressing mouse lines $[8,9]$. These mice show great promise for studying tissue-specific gene deletion and for designing more accurate models of human diseases.

It is important to note that a simple sounding goal such as generating a transgenic Cre expressing mouse line with cell type specific expression is not particularly simple to achieve. Indeed, even after a line is generated some Cre lines display activity at inappropriate times or in an unintended cell type [10]. For example, the promoter of the insulin 2 (Ins2) gene is known to direct expression only within the beta-cell population [11]; however, the Ins2-Cre Tg mouse lines showed widespread Cre activity in the brain [12]. In addition, the efficiency of Cre mediated recombination might vary at different genomic locations (LoxP sites) and segregation of the Cre $\mathrm{Tg}$ in different generations may lead to expression variation $[13,14]$. Moreover, many Cre Tg animals display unanticipated characteristics that are not always obvious in the founders [15]. Also, reduced Cre activity has been correlated with the number of generations $[16,17]$. These unexpected or varied expression patterns are major limitations in generating conditional gene-targeted mouse models. Thus, an important aspect of generating Cre driver lines is testing the spatial and temporal expression of Cre as well as its efficiency.

To obtain kidney-specifically expressed Cre driver mini-pigs, we generated two Cre $\mathrm{Tg}$ mini-pig lines expressing Cre recombinase under the control of $3.0-\mathrm{kb}$ and $8.0-\mathrm{kb}$ fragment of the mini-pig AQP2 5'-flanking region respectively. AQP2 is a water channel that is associated with renal water excretion and is thought to be preferentially expressed in the kidney collecting duct of human, mouse, and rat $[18,19]$. Previous reports have shown that Cre recombinase, when driven by mouse or human $A Q P 25$ '-flanking region, can mediate gene targeting specifically in mouse collecting duct cells [20]. As expected, the Tg mini-pigs in which the Cre expression was directed by 8-kb 5'-flanking region of $A Q P 2$ exhibit expression of Cre only in kidney collecting duct cells [21]. To our surprise, the 3-kb AQP2 5'-flanking region directed Cre expression was specifically observed in alveolar epithelial cells (AECs) instead of collecting duct cells.

The AECs participate in many essential functions including synthesis, secretion, and recycling of surfactant; and the transport of ions and water $[22,23]$. Although these AQP2Cre Tg mini-pigs express Cre recombinase outside of the intended cell type, it offers an option for investigating gene functions in AECs. In present study, we characterized the expression of Cre to confirm the utility of this Cre Tg mini-pig line and further clarified the correlation between Cre expression and genomic transgene integration. Our results demonstrate that despite the unexpected expression domain of Cre in the lungs, the expression is stable and specific over time. Combined with our previous studies of Cre recombinase activity, we believe that this Cre Tg mini-pig line will provide a reliable tool for developing AECs specific gene targeting mini-pig models. 
Table 1. Primers used. ${ }^{\mathrm{a}}$ The Cre-2 amplification primers (Cre-F2/R2) were used in both RT-PCR and Cre copy number analysis. ${ }^{b}$ Four pairs of nest primers were designed according to the 3 '- and 5 '-ends of the NheI site in the AQP2Cre vector. For the 3 '-end, the genome samples were restriction digested using HindIII and for 5'end, is EcoRV. Notably, the primer EcoRV-F2 was also used as primers SP-F1, SP-F2 and SP-F4, and HindIII-F2 was used as SP-F3. ' Four pairs of specific primers (SP) were designed according to the 3 '- or 5'- flanking sequence of AQP2-Cre and corresponding endogenous genomic DNA sequence around the integration site

\begin{tabular}{|c|c|c|c|}
\hline Name & Primers & Sequence $\left(5^{\prime} \rightarrow 3^{\prime}\right)$ & Product Size (bp) \\
\hline \multirow{2}{*}{$A Q P 2$} & AQP2-F & TGCTAGCGGTCAGGTGAGTTTCTGCCTTCT & \multirow{2}{*}{3,090} \\
\hline & AQP2-R & GAAGTACTTGTGGCTGGCCCCGGGGTCT & \\
\hline \multirow{2}{*}{ AQP2-Cre } & $\mathrm{AC}-\mathrm{F} 1$ & GGCGGCTGGACCAATGTGAATATT & \multirow{2}{*}{1,200} \\
\hline & AC-R1 & TGATGGGTGGGTAAGTTTGAAGAGT & \\
\hline \multirow{2}{*}{ Cre-1 } & Cre-F1 & GAATTCTCAATCGCCATCTTCCAGC & \multirow{2}{*}{1,044} \\
\hline & Cre-R1 & AAGCTTATGGCCAATCTCCTGACCG & \\
\hline \multirow{2}{*}{ Cre-2 a } & Cre-F2 & CACACGCGCCCTGGAAGGGA & \multirow{2}{*}{127} \\
\hline & Cre-R2 & CATGTCTCTTGCGGCTCCGA & \\
\hline \multirow{2}{*}{ GAPDH } & GAPDH-F & CACAGTCAAGGCGGAGAACGGGAA & \multirow{2}{*}{117} \\
\hline & GAPDH-R & CTCCACAACATACGTAGCACCAGC & \\
\hline \multirow{2}{*}{ TFRC } & TFRC-F & TTGAAGTGGTGGTCTTGAGGTA & \multirow{2}{*}{132} \\
\hline & TFRC-R & CGGCAATGCTGGGTCTTTAATC & \\
\hline \multicolumn{4}{|c|}{ Primers for inverse PCR b } \\
\hline \multirow{4}{*}{ HindIII (3'-end) } & F1 & CAGATTTAGGAATGAGAAGGCAGAAACT & \\
\hline & $\mathrm{R} 1$ & TCATTCTTCAACAACGATTTGCTTCCCT & \\
\hline & $\mathrm{F} 2$ & ACTGCTGAGAAAAGAAAGGACAAAAGGC & \\
\hline & R2 & ACCTAAGAAAGCAAGAGTCTCACAAGTAAGAT & \\
\hline \multirow{4}{*}{ EcoRV (5'-end) } & $\mathrm{F} 1$ & GGCATAAATATCTCACTCGCAATCAAAT & \\
\hline & R1 & GCGTGGCACAACAACTGGCGGGCAAACA & \\
\hline & $\mathrm{F} 2$ & CGCGAAATTAATACGACTCACTATAGGG & \\
\hline & R2 & CTCGACGCTCTCССTTATGCGACTCCTG & \\
\hline \multicolumn{4}{|c|}{ Specific primers (SP) for the four integration sites ${ }^{c}$} \\
\hline \multirow{2}{*}{ No.1 } & SP-F1 & CGCGAAATTAATACGACTCACTATAGGG & \multirow{2}{*}{638} \\
\hline & SP-R1 & TTTGATTGAGTGGAATGTTGGTTGC & \\
\hline \multirow{2}{*}{ No.2 } & SP-F2 & CGCGAAATTAATACGACTCACTATAGGG & \multirow{2}{*}{581} \\
\hline & SP-R2 & AGATGGAAGCACCAAAGGGCATTGA & \\
\hline \multirow{2}{*}{ No.3 } & SP-F3 & ACTGCTGAGAAAAGAAAGGACAAAAGGC & \multirow{2}{*}{305} \\
\hline & SP-R3 & GAGTGTGGCCCAACCCAGTGTGCAT & \\
\hline \multirow{2}{*}{ No.4 } & SP-F4 & CGCGAAATTAATACGACTCACTATAGGG & \multirow{2}{*}{295} \\
\hline & SP-R4 & GGTGTAGGCTGGTGGCTACAGCCAA & \\
\hline
\end{tabular}

\section{Materials and Methods}

\section{Ethics statement}

All animal studies were conducted according to the experimental practices and standards approved by the Animal Welfare and Research Ethics Committee at Jilin University (Approval ID: 2011010).

\section{Construction of the AQP2-Cre expression plasmid}

A $3 \mathrm{~kb}$ mini-pig AQP2 5' fragment was amplified from the mini-pig genome, introducing NheI and ScaI sites at the ends using primers AQP2-F/R (All primers used throughout this study are listed in Table 1). The PCR reaction was performed according to standard protocols, with the following parameters: $94{ }^{\circ} \mathrm{C}$ for $3 \mathrm{~min}$, followed by 30 cycles of $30 \mathrm{~s}$ at $95^{\circ} \mathrm{C}, 30 \mathrm{~s}$ at $66^{\circ} \mathrm{C}$, and $3 \mathrm{~min}$ at $72{ }^{\circ} \mathrm{C}$, with a final extension step at $72{ }^{\circ} \mathrm{C}$ for $5 \mathrm{~min}$. The amplified products were subjected to electrophoresis on $1 \%$ agarose gel and purified using Gel Band Purification Kit (Tiangen, Beijing, China). Then, the AQP2 5' fragment was cloned into the NheI/ScaI sites of the Cre expression vector pET28a(+)-Cre [24]. The final plasmid was named AQP2-Cre and verified by restriction enzymes and sequencing.

Generation and identification of AQP2-Cre Tg mini-pigs

The AQP2-Cre plasmid was linearized with the NheI (Fermentas, Ottawa, Canada) and transfected into Chinese mini-pig derived fetal fibroblasts using the FugeneHD reagent (Roche, Basel, Switzerland). After being cultured in selection medium containing $400 \mu \mathrm{g} / \mathrm{ml} \mathrm{G418}$ antibiotic (Amresco, Solon, OH, USA) for approximately 14 days, surviving colonies were isolated and identified by PCR using primers AC-F/R. The PCR was conducted using 30 cycles of denaturation at $94{ }^{\circ} \mathrm{C}$ for $30 \mathrm{~s}$; annealing at $64{ }^{\circ} \mathrm{C}$ for $30 \mathrm{~s}$; and extension at $72{ }^{\circ} \mathrm{C}$ for $1.5 \mathrm{~min}$. The PCR products were analyzed by electrophoresis on a $1 \%$ agarose gel and sequenced to confirm the integrity of the Cre coding sequence (CDS).

Porcine nuclear transfer was performed as described by Lai et al. [25]. To identify Tg mini-pigs, genomic DNA samples from tail tissues of the newborn mini-pigs were extracted for Southern blotting and PCR analysis. All genomic DNA samples were extracted using TIANamp Genomic DNA Kit (Tiangen) in this study. For Southern blotting analysis, $20 \mu \mathrm{g}$ of genome DNA was digested with BamHI/EcoRI restriction enzymes. The BamHI cuts once in the $3 \mathrm{~kb} A Q P 2$ 5' element and the EcoRI cuts once in the expression vector pET28a(+)Cre backbone, resulting in digesting the pig genome efficiently and forming a 3, 527 bp fragment (Fig. 1A). The hybridization probe used to detect the Cre gene $(1,044 \mathrm{bp})$ was synthesized by PCR using primers Cre-F1/R1 and labeled by PCR DIG Probe Synthesis Kit (Roche). The digested DNA was separated in a $0.8 \%$ 
agarose gel and transferred to a nylon membrane (Roche). Hybridization and chemiluminescence detection were performed following the procedures of DIG-High Prime DNA Labeling and Detection Kit II (Roche). The PCR analysis was performed using primers AC-F/R as described above. The PCR products were analyzed by electrophoresis on a $1 \%$ agarose gel and sequenced to confirm the integrity of the Cre coding sequence.

\section{RT-PCR analysis}

Total RNA was extracted from cells or tissues using the Trizol A+ kit (Tiangen). RNA from each sample $(1 \mu \mathrm{g})$ was treated with DNase I (Fermentas) and then reverse-transcribed using the BioRT cDNA First Strand Synthesis Kit (Bioer, Hangzhou, China). The cDNA samples were examined using primers Cre-F2/R2 to detect $\mathrm{Cre}$ gene respectively. Pig GAPDH was used as an internal control and amplified with the primers GAPDH-F/R. The PCR was conducted using 30 cycles of denaturation at $94{ }^{\circ} \mathrm{C}$ for $30 \mathrm{~s}$; annealing at $59{ }^{\circ} \mathrm{C}$ for Cre and $61{ }^{\circ} \mathrm{C}$ for $G A P D H$ for $30 \mathrm{~s}$; and extension at $72{ }^{\circ} \mathrm{C}$ for $15 \mathrm{~s}$. The sizes of the PCR products were $127 \mathrm{bp}$ for Cre-F2/R2 and $117 \mathrm{bp}$ for GAPDH-F/R. The PCR products were subjected to electrophoresis on a $1.5 \%$ agarose gel.

\section{Western blotting analysis}

About $3 \times 10^{6}$ cells were lysed in $80 \mu$ l IP lysis buffer $(1 \%$ Triton X-100, $150 \mathrm{mM} \mathrm{NaCl}, 0.25 \%$ sodium deoxycholate, $20 \mathrm{mM}$ Tris- $\mathrm{HCl}$, pH 7.5) to extract protein samples. For tissue samples, $5 \mathrm{mg}$ homogenized tissue was disintegrated in $100 \mu \mathrm{l}$ IP lysis buffer. The protein concentrations were measured using the BCA Protein Assay Kit (Beyotime, Haimen, China). After protein samples (25 $\mu \mathrm{g}$ ) were resolved on 10\% SDS-PAGE gels, western blotting was performed according to a standard protocol. The membranes were incubated with goat-anti Cre antibody (1:2000, Santa Cruz, Dallas, TX, USA) or mouse-anti GAPDH antibody (1:2000, Bioss, Beijing, China) at $4{ }^{\circ} \mathrm{C}$ overnight. Then, the blots were incubated with corresponding HRP-conjugated antibodies HRP-conjugated goat anti-rabbit secondary antibodies (1:8,000, Beyotime), donkey anti-goat (1:8000, Beyotime) or HRP-conjugated goat anti-mouse IgG (1:8000, Beyotime). Bands were detected using an ECL kit (Beyotime) based on the manufacturer's protocol.

\section{Immunohistochemistry analysis}

Paraffin sections were pretreated with citrate buffer $(0.01 \mathrm{M}, \mathrm{pH} 6.0)$ in $95^{\circ} \mathrm{C}$ for $10 \mathrm{~min}$ and blocked with normal goat serum. The sections were incubated with goat-anti Cre polyclonal antibody (1:800, Santa Cruz) at $4^{\circ} \mathrm{C}$ overnight and then incubated with biotin labeled rabbit anti-goat IgG antibody (1:1000, Bioss) for 20 min at room temperature. Sections were washed with PBS and incubated with avidin/HRP complex. Immunohistochemical staining was carried out using UltraSensitive ${ }^{\mathrm{TM}}$ SP IHC Kit (Maxim, Fuzhou, China). Diaminobenzidine (Maxim, Fuzhou, China) was used for the color reaction, and the sections were analyzed by microscopy (Olympus CellSens Dimension).

\section{Testing the AQP2-Cre vector in vitro}

Initial in vitro analysis of the AQP2-Cre plasmid was performed two rounds. The first round was performed following the plasmid construction. The AQP2-Cre plasmid was transiently transfected into LLCPK1 cells to estimate the expression of Cre recombinase. The second round in vitro expression analysis was performed after confirming Cre expression patterns in Tg mini-pigs. In the second round, the plasmid was transiently transfected into PK15, Hela, A549, HepG-2, and LLC-PK1 cells to assess the specificity of the AQP2Cre construct. PK15 (pig kidney epithelial cell lines), Hela (human cervical fibroblasts lines), and HepG-2 (human hepatocellular carcinoma HepG 2 cell lines) cell lines, obtained in our laboratory, were purchased from American Type Culture Collection (ATCC); LLC-PK1 (pig kidney proximal tubule cell lines) cell lines were obtained from ATCC; A549 (human alveolar basal epithelial cell lines) cell lines were generously provided by Professor Ziyi Li at Jilin University. Briefly, cells were maintained in DMEM (Fermentas, Ottawa, Canada) supplemented with 5\% fetal bovine serum (FBS) (Life Technologies, Grand Island, NY, USA), 1\% penicillin/streptomycin (Gibco, Grand Island, NY, USA), at $37{ }^{\circ} \mathrm{C}, 5 \% \mathrm{CO}_{2}$ in humidified air. For transient transfections, cells were seeded at $1.2 \times 10^{5} \mathrm{cells} / \mathrm{cm}^{2}$ in six-well plates (Nunc, Roskilde, Denmark). Six hours after seeding, the cells were transfected using the FugeneHD (Roche, Basel, Switzerland) according to the manufacturer's instructions. A total of $3.5 \mu \mathrm{g}$ of circular AQP2-Cre plasmid and $10 \mu \mathrm{l}$ of FugeneHD were added to $86.5 \mu \mathrm{l}$ of DMEM and incubated at room temperature for $15 \mathrm{~min}$ before the mixture was added to the culture medium. The cells were respectively harvested at 48 and 72 hours in the first round and at 48 
in the second round after the transfection. The expression of Cre recombinase was determined by RT-PCR and western blot analysis.

\section{Relative qRT-PCR analysis}

To examine variations in Cre expression over time and in subsequent generations, qRT-PCR was performed. Extraction and treatment of total RNA were described as above. The Cre expression was examined using primers Cre-F2/R2 and GAPDH was used as an internal control. The qRT-PCR was performed using SYBR Premix Ex Taq Kit (Bioer) and the Bio-Rad Real-Time PCR System (Bio-Rad, Hercules, CA, USA). Amplification was performed under the following conditions: one cycle at $94{ }^{\circ} \mathrm{C}$ for $2 \mathrm{~min}$, then 40 cycles at $94{ }^{\circ} \mathrm{C}$ for $10 \mathrm{~s}$, and $60^{\circ} \mathrm{C}$ for $30 \mathrm{~s}$. For each test sample, a standard qPCR was performed in six replicates. A melting curve analysis was also conducted following amplification to test for primer dimers and other nonspecific products. The delta CT for both the Cre and GAPDH are means of six replicates.

\section{Analysis of copy number by absolute qRT-PCR}

Copy number analysis was performed as described by Ingham et al. [26]. Briefly, Cre was detected using Cre-F2/R2 primers, and the transferrin receptor (TFRC) gene was amplified as a reference with the primers TFRC-F/R. Two rounds of absolute qRT-PCR, based on the standard curves with different resolution, were performed. In the first round, the standards were prepared by mixing different amounts of AQP2-Cre plasmid with 50 ng wild-type mini-pig genomic DNA to achieve 1, 2, 4, 8, 16, 32, 64 and 128 copies of the Cre gene per haploid genome. To prepare a standard sample containing one Cre gene copy per haploid genome, the mass of AQP2-Cre plasmid required for mixing with the $50 \mathrm{ng}$ wild-type genomic DNA was determined by: $\frac{a \times b \times 0.5}{2.9 \times 10^{9}}$ ng (where ' $a$ ' represents the plasmid size in $\mathrm{kb}$, and ' $b$ ' represents the mass of wild-type genomic DNA in ng). Then, the different masses (in ng) of AQP2-Cre plasmid were calculated and mixed with $50 \mathrm{ng}$ of wild-type genomic DNA. The qRT-PCR assays were performed as described above. Amplification was performed under the following conditions: one cycle at $94^{\circ} \mathrm{C}$ for $2 \mathrm{~min}$, then 40 cycles at $94^{\circ} \mathrm{C}$ for $10 \mathrm{~s}$, and $60^{\circ} \mathrm{C}$ for Cre and $61.5^{\circ} \mathrm{C}$ for $T F R C$ for $30 \mathrm{~s}$. For each standard and test sample qPCR was performed in triplicate. A standard curve was constructed by plotting the $\Delta \mathrm{C}_{\mathrm{t}}\left(\Delta \mathrm{C}_{\mathrm{t}}=\mathrm{C}_{\mathrm{tCre}}-\mathrm{C}_{\mathrm{tTFRC}}\right)$ values against the log of the Cre gene copies from the corresponding standard templates.

In the second round, a standard curve with proportionate resolution was used according to the Cre copy number values detected in the first round of qRT-PCR. The standards preparation and the qRT-PCR assays were performed as described above.

\section{Integration site analysis by inverse PCR}

One microgram of genomic DNA was digested with restriction endonucleases at $37{ }^{\circ} \mathrm{C}$ overnight. The restriction digestions were performed using HindIII (for 3'- end) and EcoRV (5'-end). After restriction enzyme digestion, the genomic fragments were treated with T4 DNA polymerase followed by ligation using T4 DNA ligase. Then, 100 ng of circularized DNA was amplified and $2 \mu \mathrm{l}$ of this primary PCR product was used as the template in the second round of PCR using nested primers (NH-F/R and NE-F/R). The PCR was conducted using 30 cycles of denaturation at $94{ }^{\circ} \mathrm{C}$ for $30 \mathrm{~s}$; annealing at $57.5^{\circ} \mathrm{C}$ for primary PCR and 63.5 for the second round PCR for $30 \mathrm{~s}$; and extension at $72{ }^{\circ} \mathrm{C}$ for $4 \mathrm{~min}$. PCR products were gel-extracted and sequenced. The sites of integration were determined by BLAST-searching the pig genome database on NCBI.

To verify the integration sites, the genomic DNA samples from all Tg mini-pigs were further analyzed by PCR using specific primers (SP). These specific primers were designed according to the 3'- or 5'- flanking sequence of AQP2-Cre (forward primers) and corresponding endogenous genomic DNA sequence around the integration site (reverse primers). PCR was performed with the following parameters: $94{ }^{\circ} \mathrm{C}$ for $3 \mathrm{~min}$, followed by 30 cycles of $30 \mathrm{~s}$ at $95^{\circ} \mathrm{C}, 30 \mathrm{~s}$ at $59^{\circ} \mathrm{C}$ for SP $1,62^{\circ} \mathrm{C}$ for SP $2,57^{\circ} \mathrm{C}$ for SP 3 and $59{ }^{\circ} \mathrm{C}$ for SP 4 , and $15 \mathrm{~s}$ at $72{ }^{\circ} \mathrm{C}$, with a final extension step at $72{ }^{\circ} \mathrm{C}$ for $5 \mathrm{~min}$. PCR products were gel-extracted and sequenced.

\section{Statistical analyses}

Statistical analysis was performed using SPSS 17.0. All results are shown as mean \pm SD values. Relative gene expression was determined using the $2^{-\Delta \Delta C t}$ method built into the thermocycler software. One-way ANOVA followed by a Student-Newman-Keuls test was used to assess the differences between groups. Values of $\mathrm{P}=<0.05$ were considered statistically significant. 


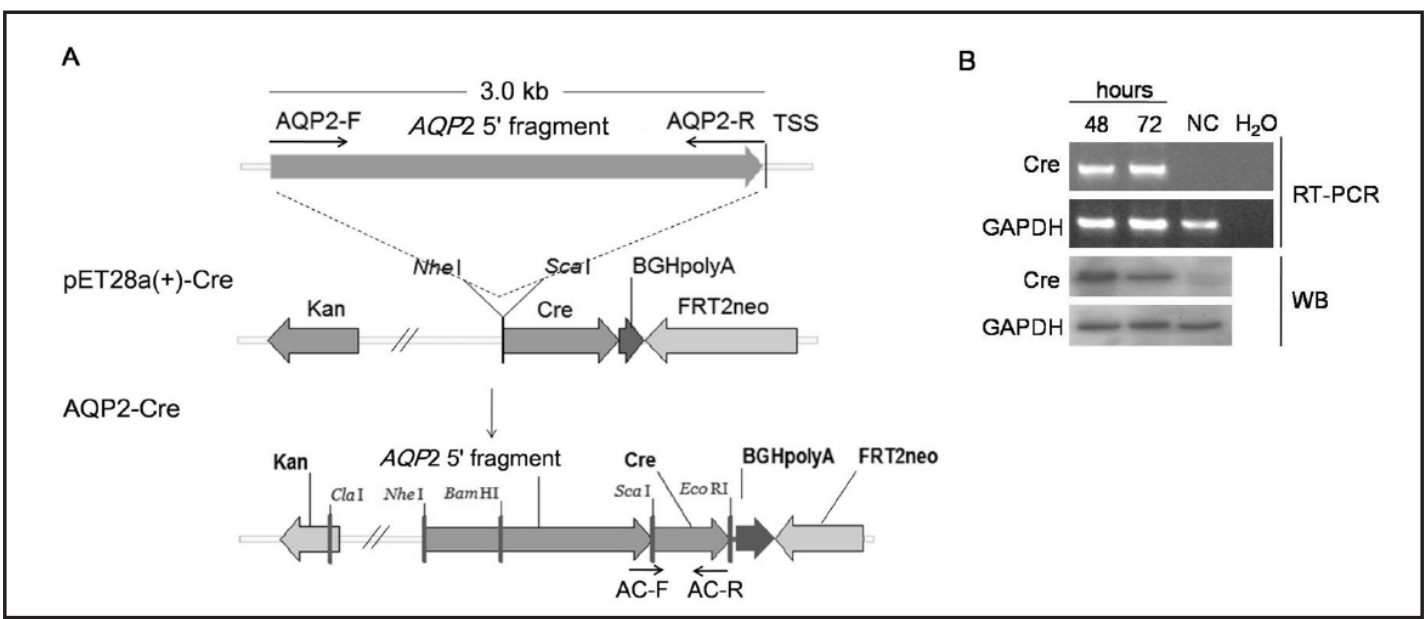

Fig. 1. Construction of AQP2-Cre plasmid and in vitro Cre expression analysis. (A) Construction of AQP2-Cre expression vector. The expression of Cre was controlled by a 3-kb fragment of the mini-pig $A Q P 2$ 5'-flanking region. A transcriptional termination sequence (BGHployA) was attached to downstream of Cre and a pgkneo expression cassette flanked by FRT sites (FRT2neo) was linked to the construct for selection. The total size of the vector is $11,046 \mathrm{bp}$. The primers AC-F/R were used to identify AQP2-Cre positive cell clones and Tg mini-pigs. The restriction enzymes sites, BamHI and EcoRI, used in southern blotting analysis, were shown. TSS=transcription start site. (B) Expression of AQP2-Cre plasmid in LLC-PK1 cells. The expression of AQP2-Cre was analyzed by RT-PCR and western blotting (WB). The Cre recombinase was measured in LLCPK1 cells transfected with AQP2-Cre, but not in non-transfected cells (negative control, NC). GAPDH was used as a positive control in each test; water was served as negative control in RT-PCR analysis.

\section{Results}

AQP2-Cre plasmid construction and in vitro expression analysis

The AQP2-Cre plasmid was constructed as shown in Fig. 1A. After verified by sequencing, the AQP2-Cre plasmid was transiently transfected into LLC-PK1 cells to estimate the expression of Cre recombinase. As shown in Fig. 1B, the Cre recombinase can be detected at transfected LLC-PK1 cells, showing that a 3-kb fragment of the pig AQP2 5'-flanking region can efficiently direct the expression of Cre recombinase in LLC-PK1 cells.

\section{Generation and identification of AQP2-Cre Tg mini-pigs}

Cells from a single surviving colony of mini-pig transfected fibroblasts were selected as nuclear donors for pig somatic cell nuclear transfer (SCNT) and a total of 1427 reconstructed embryos were transferred to five recipient female pigs. Two recipients miscarried all embryos during pregnancy and the other three produced twelve male mini-pigs. Of these mini-pigs, two died during delivery (No.0665 and No.0681) and four died soon after birth (No.0671, No.0679, No.0685, and No.0687) leaving six founder piglets (Table 2). The piglets appeared to be normal in size, morphology, and behavior (Fig. 2A). The average birth weight of those 12 cloned mini-pigs was $0.95 \mathrm{~kg}$.

Tail tissue from all 12 newborn cloned mini-pigs was collected for transgeneidentification and fibroblast isolation. The integration of Cre recombinase gene was confirmed by Southern blotting and PCR analysis, and the results revealed that all of the mini-pigs were positive for the transgene (Fig. 2B, 2C). Sequencing results showed that all of them had integrated the complete Cre CDS.

To generate F1 transgenic mini-pigs, five month old Tg mini-pig, No.0677, was mated with a female wild-type mini-pig. Five F1 mini-pigs were born from one litter (Fig. 2A). One female (No.2448) and two male (No.2513 and No.2517) mini-pigs were confirmed to be transgenic by PCR analysis (Fig. 2C). Here, the genotype of AQP2-Cre Tg mini-pig lines segregated in subsequent generations, which is a common observation in Tg animals. 
A

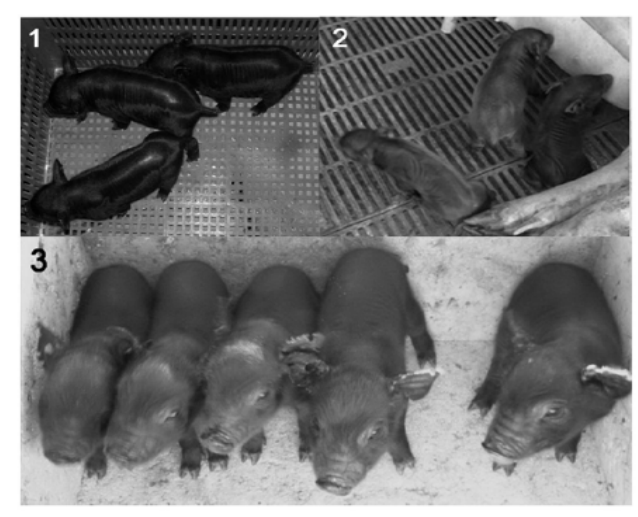

B

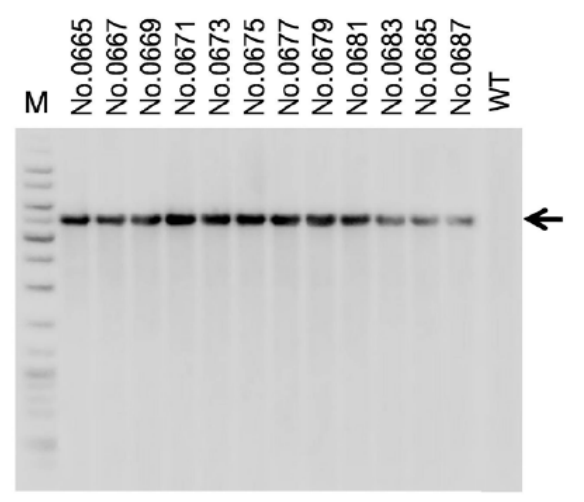

F1

C

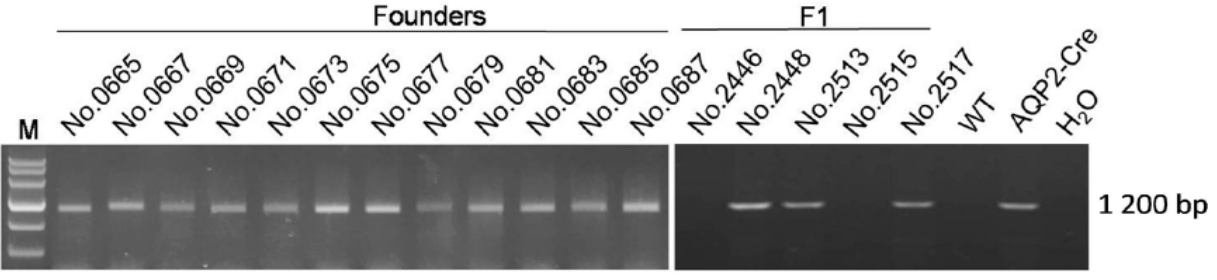

Fig. 2. Generation of AQP2-Cre Tg mini-pigs. (A) Six surviving founder mini-pigs (A1 and A2) and offspring of No.0677 (A3). (B) Southern blotting analysis of Cre gene in transgenic pigs. Genome DNA from the 12 founder piglets were digested with BamHI/EcoRI restriction enzymes (as shown in Fig. 1A). The arrow indicates 3,527 bp DNA bands. Lane M represents $10.0 \mathrm{~kb}$ DNA ladder Marker. (C) PCR identification of the Cre gene in Tg mini-pigs. All 12 founder mini-piglets and three (No.2448, No.2513, No.2517) of five offspring were positive for the Cre gene. The expected size of PCR products was $1200 \mathrm{bp}$. Lane M represents DNA Marker III. A wild-type mini-piglet genomic sample (WT) served as negative control in both southern blotting and PCR analysis.

Table 2. Embryo transfer, pregnancy, and newborn mini-pig information. ${ }^{\mathrm{d}}$ Mini-pigs died during delivery. ${ }^{\mathrm{e}}$ Mini-pigs died after birth

\begin{tabular}{lcl}
\hline Pregnancy & Embryos transfered & \multicolumn{1}{c}{ Mini-pigs } \\
\hline No.378 & 244 & miscarried during pregnancy \\
No.329 & 254 & $0665^{\mathrm{d}}$ 0667 0669 0671 0673 \\
No.496 & 296 & 0675 0677 0679e 0681d \\
No.485 & 313 & 0683 0685 0687 \\
No.457 & 320 & miscarried during pregnancy \\
\hline
\end{tabular}

Expression pattern of Cre recombinase in various organs of the FO and F1 Tg mini-pigs

The Cre expression pattern in the Tg mini-pigs was analyzed by RT-PCR and western blotting. Tissues from the four founder Tg mini-pigs, No.0679, No.0681, No.0685 and No.0687, that died during delivery or shortly after birth, and from one of the male offspring (No.2513) were used for analysis. Total RNA and protein samples were extracted from the heart, liver, spleen, lung, kidney, skeletal muscle, blood vessel, and testes. Our data showed that of the tissues analyzed, Cre was only expressed in lung tissue of founder Tg mini-pigs (Fig. 3-left and right). The F1 generation Tg mini-pig, No.2513, also showed exclusively lung expression of Cre (Fig. 3-middle).

To determine which cells were specifically expressing Cre in the lung, we performed IHC analysis on various tissues of mini-pigs No.0679 and lung tissue of No.2513 (Fig. 4). Cre staining was observed in AECs of F0 and F1 Tg mini-pigs (Fig. 4D and 4I). Of note, Cre was located in the nucleus and cytoplasm of the epithelial cells (indicated by red arrows) (Fig. $4 \mathrm{~J})$. 


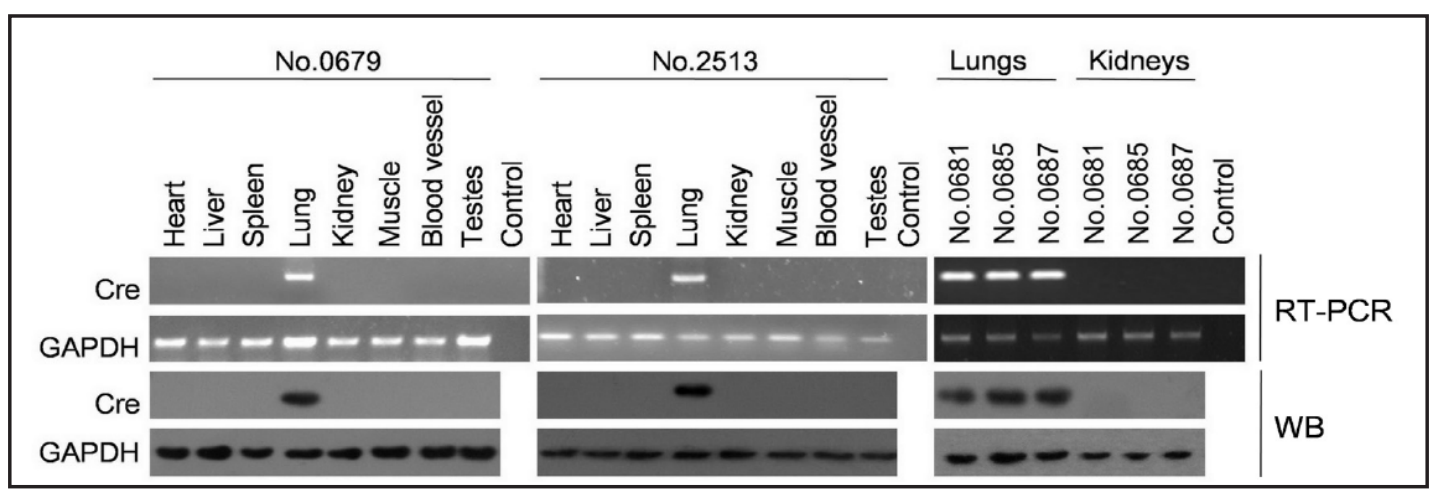

Fig. 3. Expression analysis of Cre recombinase. Heart, liver, spleen, lung, kidney, muscle, blood vessel, and testicle tissues from No.0679 and No.2513 Tg mini-pigs were assessed by using RT-PCR and western blotting (WB). The No.0679 was used as representative of F0 generation, and the No.2513 (offspring of No.0677) was representative of F1 generation. Out of the analyzed tissues Cre was expressed in lung tissues both in F0 (No.0679, left) and F1 (No.2513, middle) Tg mini-pigs. Kidney and lung tissues from three other F0 Tg mini-pigs (No.0681, No.0685 and No.0687) were also assessed. Cre was expressed in the lung tissues of all tested mini-pigs (right). The expected sizes of PCR products were $127 \mathrm{bp}$ for Cre-F2/R2 and $117 \mathrm{bp}$ for GAPDH-F/R primer pairs. GAPDH was used as a positive control in each test; water served as the negative control (Control) in RT-PCR.

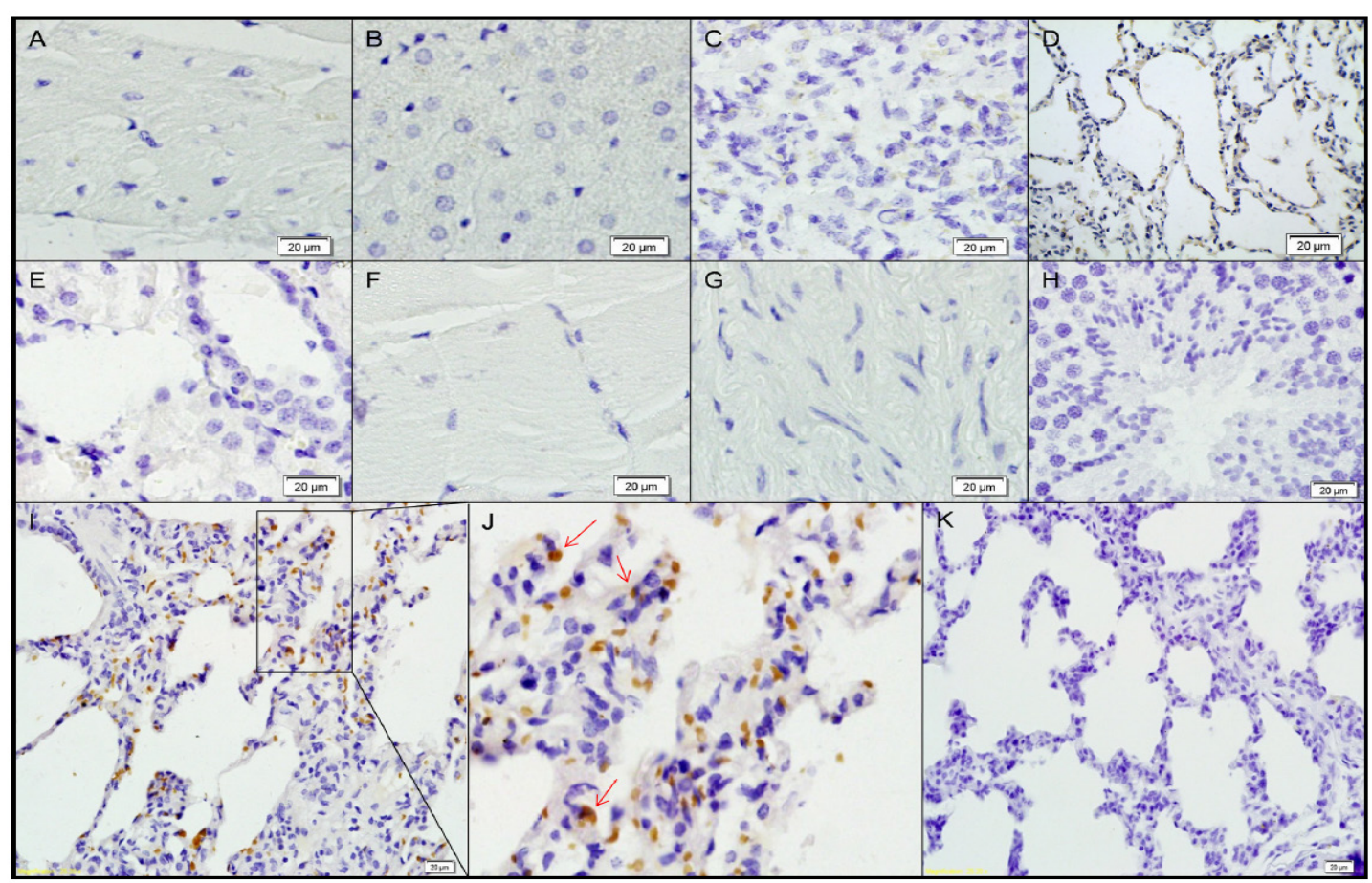

Fig. 4. Cellular expression of Cre recombinase. Several tissues namely heart(A), liver(B), spleen(C), lung(D), kidney(E), muscle(F), blood vessel(G), and testes(H) from No.0679 (representative of F0 generation) and lung tissues (I) from No.2513 (representative of F1 generation) Tg mini-pigs were analyzed by immunohistochemistry (IHC). Cre was detected in the nucleus and cytoplasm of alveolar epithelial cells (red arrows) (J). Lung tissue from a wild-type mini-pig was used as negative control (K). The expression of Cre recombinase was shown by brown color, and nuclei were stained blue.

Specificity analysis of AQP2-Cre plasmid in vitro

As the AQP2-Cre Tg mini-pigs exhibit unanticipated Cre expression in lung tissues, we subsequently performed the in vitro expression analysis of the AQP2-Cre plasmid. Five cell lines named PK15, Hela, A549, HepG-2 and LLC-PK1 were transiently transfected with AQP2- 
Fig. 5. Expression of AQP2-Cre in different cell lines. Five cell lines, PK15, Hela, A549, HepG-2, and LLCPK1 were transiently transfected with the AQP2-Cre plasmid. Cre expression was evident in AQP2-Cre transfected LLC-PK1 cells both in RT-PCR and western blotting (WB) analysis. The expected sizes of PCR products were $127 \mathrm{bp}$ for Cre-F2/R2 and 117 bp for GAPDH-F/R primer pairs. GAPDH was used as a positive control in each test; water served as negative control (Control) in RT-PCR analysis.

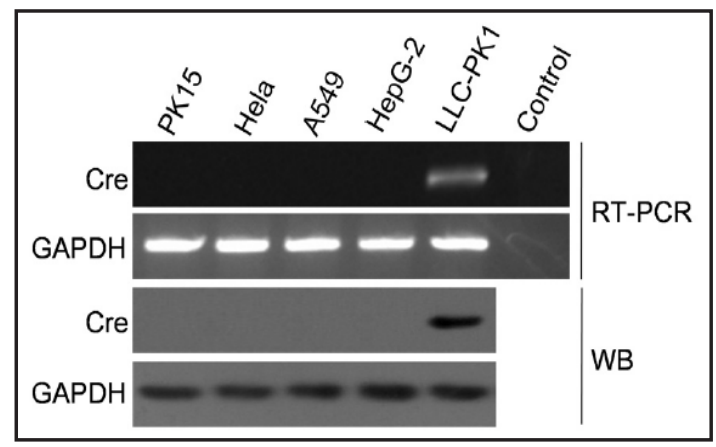

Table 3. Cre copy number values in different newborn Tg mini-pigs ${ }^{\mathrm{f}}$. The standard curve was defined as: $\log _{2} N=-0.9176 \Delta C_{t}+2.561\left(r^{2}=0.9882\right)$

\begin{tabular}{lrlr}
\hline Pigs & \multicolumn{1}{c}{ Cre copies } & Pigs & Cre copies \\
\hline No.0665 & $8.52 \pm 1.35$ & No.2448 & $5.08 \pm 0.96$ \\
No.0667 & $9.85 \pm 1.37$ & No.2513 & $6.97 \pm 0.98$ \\
No.0669 & $10.96 \pm 1.31$ & No.2517 & $5.32 \pm 1.39$ \\
No.0671 & $9.16 \pm 0.73$ & & \\
No.0673 & $8.58 \pm 0.88$ & & \\
No.0675 & $9.24 \pm 0.97$ & & \\
No.0677 & $10.39 \pm 0.87$ & & \\
No.0679 & $10.45 \pm 0.69$ & & \\
No.0681 & $11.16 \pm 1.09$ & & \\
No.0683 & $10.53 \pm 0.97$ & & \\
No.0685 & $9.88 \pm 0.93$ & & \\
No.0687 & $9.57 \pm 1.16$ & & \\
\hline
\end{tabular}

Table 4. Cre copy number values in various tissues $g$. gThe standard curve was defined as: $\log _{2} \mathrm{~N}=-0.9045 \Delta \mathrm{C}_{\mathrm{t}}$ $+1.9571\left(r^{2}=0.9809\right)$

\begin{tabular}{lrrc}
\hline & \multicolumn{3}{c}{ Cre copies } \\
Tissue & \multicolumn{1}{c}{ No.0679 } & \multicolumn{1}{c}{ No.0685 } & No.2513 \\
\hline Heart & $9.38 \pm 1.23$ & $9.74 \pm 1.59$ & $5.80 \pm 1.45$ \\
Liver & $10.43 \pm 1.13$ & $8.89 \pm 1.46$ & $6.08 \pm 0.76$ \\
Spleen & $8.94 \pm 1.27$ & $10.17 \pm 2.26$ & $6.21 \pm 0.72$ \\
Lung & $10.28 \pm 1.49$ & $9.91 \pm 1.37$ & $5.93 \pm 1.61$ \\
Kidney & $9.78 \pm 1.18$ & $10.39 \pm 1.19$ & $6.50 \pm 1.27$ \\
Muscle & $10.18 \pm 0.98$ & $10.98 \pm 1.21$ & $5.97 \pm 1.00$ \\
Blood vessel & $10.58 \pm 1.22$ & $9.18 \pm 1.53$ & $5.80 \pm 0.86$ \\
Testes & $8.75 \pm 1.20$ & $10.53 \pm 1.49$ & $7.07 \pm 0.80$ \\
\hline
\end{tabular}

Cre plasmid. Total RNA and protein samples extracted from AQP2-Cre transfected cells were examined respectively. As shown in Fig. 5, the Cre recombinase can been detected only in AQP2-Cre transfected LLC-PK1 cells, but not in PK15, Hela, A549, and HepG-2 cells.

\section{Analysis of Cre copy number in Tg mini-pigs}

We next analyzed the copy number of the AQP2-Cre transgene in the mini-pigs. To estimate the copy number of the AQP2-Cre transgene more accurately, we performed two rounds of absolute qRT-PCR using two standard curves with different resolution respectively. In the first round, we confirmed that the Cre copy number values of founders ranged from 8.20 to 11.41. Therefore, a standard curve with 15 points where standards ranged from 1 to 15 copies was used in the second round. Genomic DNA samples, extracted from tail tissues from each $\mathrm{Tg}$ mini-pig and from the other tissues (as above) harvested from piglets No.0679, No.0685, and No.2513 were analyzed. As showing Table 3 and 4, the Cre copies of founders and various tissues of a single founder mini-pig were ranged from 8 to 11 . These data revealed that the Cre copies varied in the different founder Tg mini-pigs and various tissues, but that these differences were not significant $(\mathrm{P}>0.05)$ (Fig. 6A, 6B), which is consistent with previous reports [27]. The analysis of the F1 Tg mini-pigs showed only 5 to 6 Cre copies present in the different Tg mini-pigs and in the various tissues of No.2513 (Table 3 and 4). The observed Cre copies were varied, but the difference between the lowest and highest values ( 5 and 6 copies, respectively) was not significant ( $\mathrm{P}>0.05$ ) (Fig. 6A and 6B).

\section{Analysis of Cre expression changes with aging and in subsequent generations}

To confirm whether this Tg mini-pig line will stably express Cre recombinase with aging, the founder Tg mini-pigs, No.0687 (two days old), No.0683 (one month old), No.0677 (five months old), No.0675 (ten months old), and No.0673 (fifteen months old) were used to obtain lung tissues. Firstly, we analyzed the genomic integration copy number of different mini-pigs by absolute qRT-PCR. Genomic DNA samples extracted from these lung tissues 
Fig. 6. Analysis of Cre copy number in different founder Tg mini-pigs and various tissues. (A) Cre copy number in different newborn Tg mini-pigs. There was no statistically significant difference in the 12 founder Tg mini-pigs $(\mathrm{P}=0.146>0.05)$. The Cre copy number varied but was not different in the three offspring

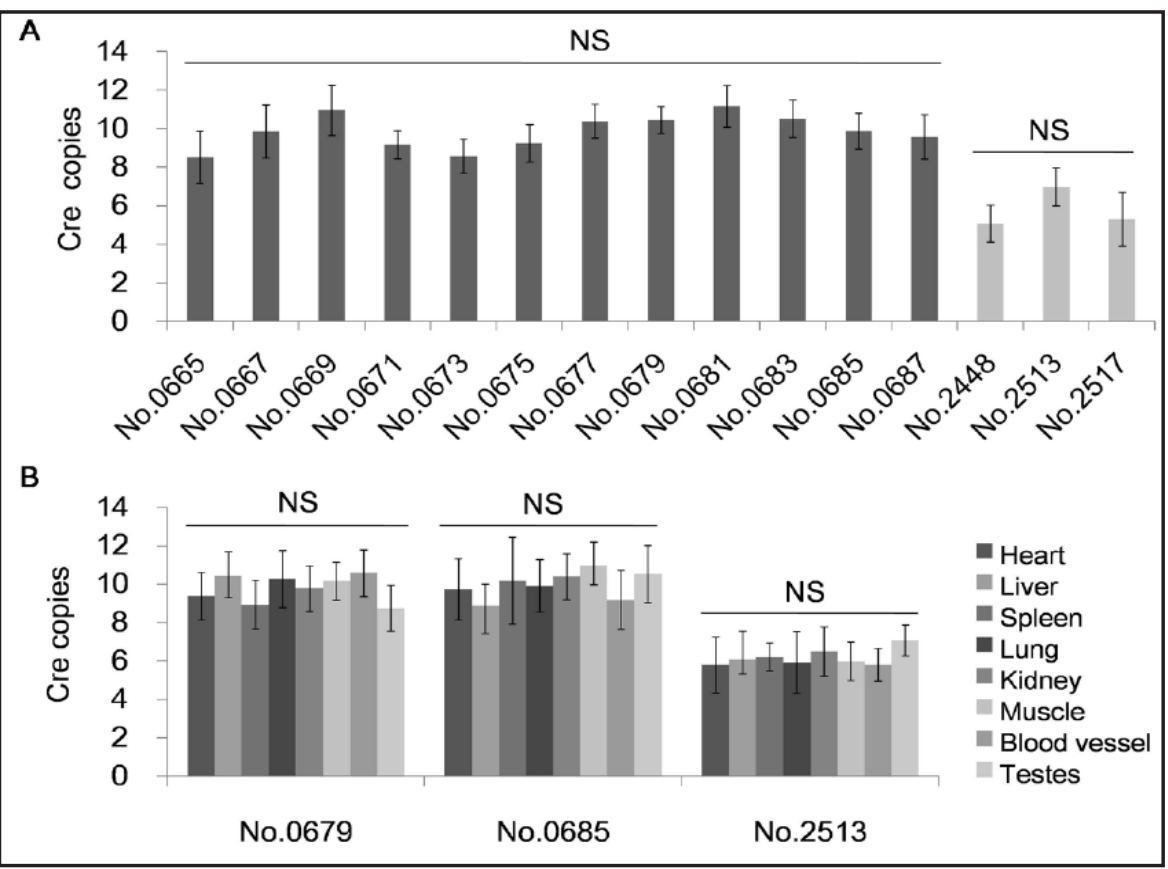
$(\mathrm{P}=0.176>0.05)$. (B) Cre copy number in various tissues from piglet No.0679, No.0685 and No.2513. The copy numbers are not significantly difference in any single mini-pig, No.0679 ( $\mathrm{P}=0.607>0.05)$, No.0685 $(\mathrm{P}=0.710>0.05)$, and No.2513 $(\mathrm{P}=0.838>0.05)$. Data represent the means $\pm S D, n=3$ per group. NS=not significant.

Table 5. Cre copy number values in lung tissue from Tg mini-pigs at different ages ${ }^{\mathrm{h}}{ }^{\mathrm{h}}$ The standard curve was defined as: $\log _{2} \mathrm{~N}=-0.9312 \Delta \mathrm{C}_{\mathrm{t}}+2.062\left(\mathrm{r}^{2}=0.9901\right)$

\begin{tabular}{lccccc}
\hline Age (months) & Newborn & 1 & 5 & 10 & 15 \\
\hline Cre copies & $10.88 \pm 0.43$ & $10.46 \pm 0.99$ & $10.06 \pm 1.37$ & $9.46 \pm 0.97$ & $9.09 \pm 1.62$ \\
\hline
\end{tabular}

were examined. The results indicated that the Cre copy number in different Tg mini-pigs varied, but the difference was not significant (Table 5) (P>0.05) (Fig. 7A). Based on the Cre copy number analysis results, we analyzed the relative Cre expression levels in these founder $\mathrm{Tg}$ mini-pigs by relative qRT-PCR analysis. Total RNA samples extracted from the lung tissue of the mini-pigs described above ( 2 days old - 15 months old; No.0687, No.0683, No.0677, No.0675, and No.0673) were used in Cre expression analysis by relative qRT-PCR. The data revealed that the Cre expression levels in the founder Tg mini-pigs varied over time, but not significantly ( $\mathrm{P}=0.075>0.05$ ) (Fig. $7 \mathrm{C}$ ).

We also analyzed the relative Cre expression changes between a founder mini-pig (No.0677, at 5 months old) and its offspring (No.2513, newborn). Although the genomic Cre copies between tails from mini-pig No.0677 and his offspring showed a significant decrease after passage $(\mathrm{P}<0.05)$ (Fig. 7B), the Cre expression levels didn't significantly changed after passage $(\mathrm{P}=0.381>0.05)$ (Fig. 7D). These findings suggested that this $\mathrm{Tg}$ mini-pig line can stably express Cre recombinase in founders and the first generation.

\section{Analysis of AQP2-Cre integration sites in Tg mini-pigs}

In this study, the Cre expression vector was introduced randomly into the host genome. The unexpected expression domain of the AQP2-Cre could be caused by positional effects of random insertion. Therefore, we performed inverse PCR to analyze the integration sites of the AQP2-Cre vector in Tg mini-pigs. After two round inverse PCR, a total of eight PCR products were sequenced, and four insertion sites were identified (Table 6). We observed that the AQP2-Cre plasmids integrated in both intergenic regions and within genes. Plasmid 
Fig. 7. Analysis of Cre copies and expression levels over time and generations. (A) Cre copy number changes with aging. Genomic DNA samples extracted from the lung tissue of founder Tg minipigs at different ages were analyze by absolute qRT-PCR. The Cre copy number varied but not significantly in different ages

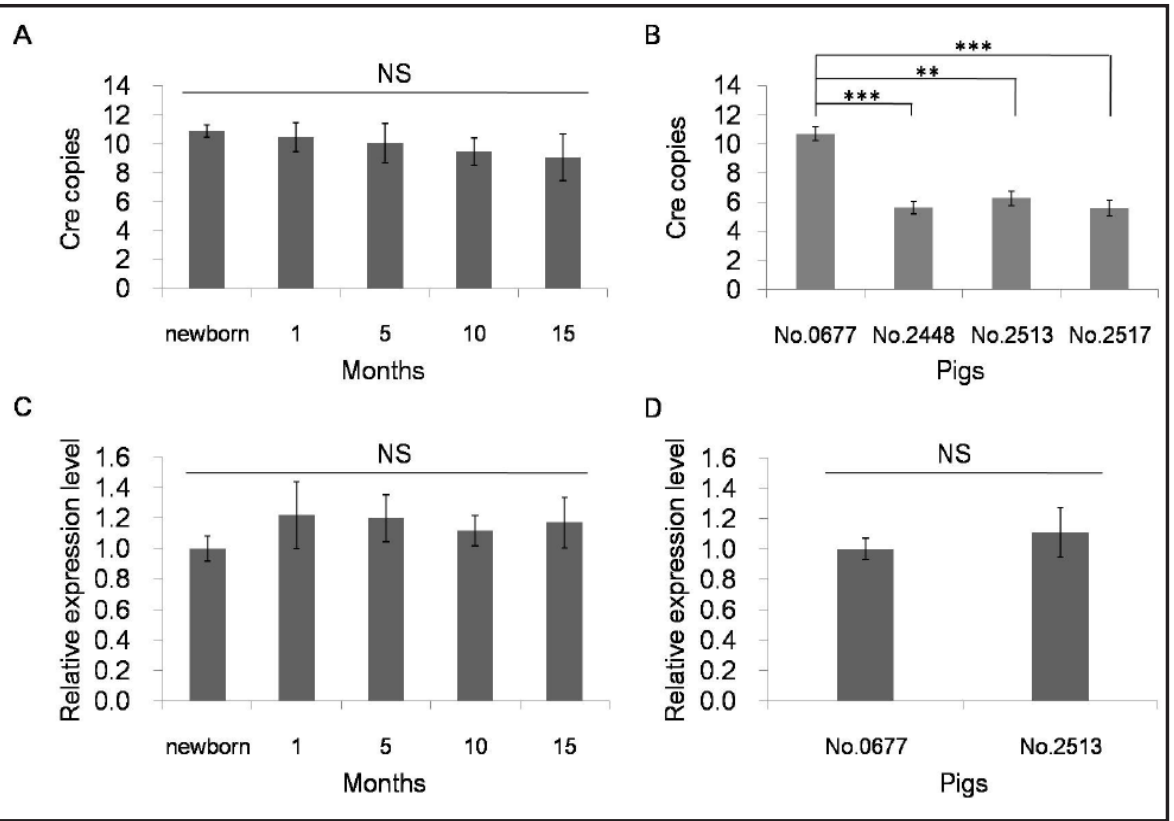

$(\mathrm{P}=0.376>0.05)$. (B) Cre copy number in No.0677 and his offspring. The results showed that the decrease in copy number from founder to offspring was significant. (C) Relative Cre expression levels of founder $\mathrm{Tg}$ mini-pigs at different ages. (D) Relative Cre expression levels between founder (No.0677) and offspring (No.2513) Tg mini-pigs. The Cre expression is stable with aging $(\mathrm{P}>0.05)$ and in subsequent generations $(P>0.05)$. Data represent the means $\pm S D, n=6$ per group in Cre expression level analysis. Statistical relevance is shown: ${ }^{* *} \mathrm{P}<0.01,{ }^{* * *} \mathrm{P}<0.005$. NS=not significant.

Table 6. Chromosome integration sites of AQP2-Cre. Integration sites were detected by different primers, which designed according to the 3 '- or $5^{\prime}$-ends of NheI site in the parent vector. 'TRPV2, transient receptor potential cation channel, subfamily V, member 2 (TRPV2); TMEM163, transmembrane protein 163; AOAH, acyloxyacyl hybrolase. ${ }^{k} G e n e s$ located from within $\pm 50 \mathrm{~kb}$ of the integration sites. CENPV, processing of precursor 1 ; FAM211A, centromere protein $V$, family with sequence similarity 211 , member A; UBB, ubiquitin B; MGAT5, mannosyl (alpha-1,6-)-glycoprotein beta-1,6-N-acetyl-glucosaminyl transferase ; ANAL, anillin, actin binding protein

\begin{tabular}{lllll}
\hline ID & End $^{\mathrm{i}}$ & Chr. & Nearest gene & Genes located around the integration site \\
\hline 1 & 5 & 4 & 1.9 kb upstream of NIPA-like protein 2 & POP1 \\
2 & 5 & 12 & 0.4 kb upstream of TRPV2 & CENPV, FAM211A, UBB \\
3 & 3 & 15 & 2.4 kb downstream of TMEM163 & MGAT5 \\
4 & 5 & 18 & 0.8 kb upstream of AOAH & ANAL \\
\hline
\end{tabular}

vectors tended to integrate within introns if the integration sites were in genes. Then, genomic DNA samples from the 12 founders and 3 offspring Tg mini-pigs were assayed by PCR using specific primers. We determined that all four integration sites were present in the 12 founders and 2 male offspring (No.2513 and No.2517), while only three integration sites (ID 1, 2, 3) were detected in piglet No.2448 (Fig. 8).

\section{Discussion}

Pigs are similar to humans in organ size, structure, and physiology; thus developing conditional pig models will be an exciting biomedical feat [28]. Recent advances in pig SCNT have made it possible to utilize Cre/loxP strategy in developing pig models. Leuchs $\mathrm{S}$ et.al described a targeted pig line carrying an inducible TP53 R167H allele orthologous 


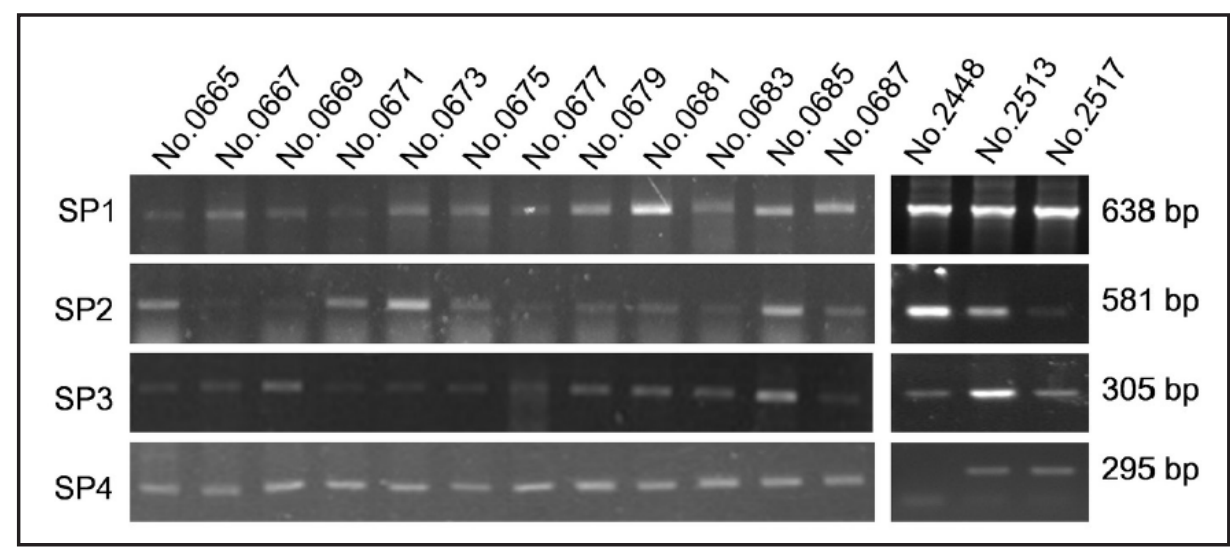

Fig. 8. Integration site analysis of the different Tg mini-pigs. Tail genomic DNA samples from different newborn Tg mini-pigs was analysis by four specific primer pairs (SP1-4). All four integration sites were present in the tested samples except for No.2448, in which only three integration sites were detected. The integration site, ID.4, was absent in No.2448.

to the human TP53 R175H mutation [29]. This line can be used to investigate Li Fraumeni syndrome and to decipher the oncogenic characteristics of p53 mutations found in human cancers. In addition, the generation and investigation of other Cre Tg pigs has recently been reported [24, 30, 31]. The development of diagnoses and therapies for human diseases requires convincing animal model data. Therefore, well characterized Cre Tg pig lines with stable and specific expression are urgently needed.

The aim of this study was the generation of a kidney specific Cre mini-pig line. Previous reports have demonstrated that $A Q P 2$ is expressed in the kidney collecting duct cells of mice [32], rats [33], and humans [18]. Skowronski and colleagues reported that $A Q P 2$ expression occurred in the inner medullary collecting ducts of female pig kidney [34]. Our previous study revealed that endogenous $A Q P 2$ was expressed in kidney tissues of male pigs [21]. We therefore selected mini-pig AQP2 5'-flanking region in hopes of creating Tg mini-pigs in which Cre recombinase was specifically expressed in kidney collecting duct cells.

How long mini-pig $A Q P 25$ '-flanking fragment is sufficient to direct the kidney-specific expression of Cre in Tg mini-pigs? Previous studies suggested that transcriptional regulators (TRs), binding to cAMP-responsive element-binding proteins (CREB), retinoid X receptor (RXR), Homeobox (HOX) and GATA elements, are involved in cell-specific regulation of $A Q P 2$ gene expression. These TRs binding elements are present in two highly conserved regions (513 and 224 bp upstream from transcription start site) of human and mouse AQP2 5 '-flanking [35]. Sequence conservation analysis suggested that about $1500 \mathrm{bp}$ upstream from the transcription start site of $A Q P 2$ gene is highly conserved promoter region. In this study, a 3-kb mini-pig $A Q P 2$ 5'-flanking region was used to include all species-specific transcriptional regulators binding elements (TRBEs) in pig $A Q P 2$ promoter region. In addition, Cre recombinase has been shown to mediate cell-specific gene inactivation in mouse collecting duct cells under the control of the 11-14 kb mouse or human AQP2 5'-flanking region [20]. For instance, Guan and colleagues developed an AQP2-Cre mouse strain, using $14 \mathrm{~kb}$ of the mouse $A Q P 25$ '-flanking region, to specifically delete the peroxisome proliferator-activated receptor sublype gamma (PPAR $\gamma$ ) in collecting duct cells [36]. Similarly, Zhang et al. used a $\mathrm{Tg}$ mouse strain for Cre recombinase driven by $11 \mathrm{~kb}$ of the mouse $A Q P 25^{\prime}$-flanking region to remove the PPAR $\gamma$ exclusively from collecting duct cells [37]. Accordingly, we constructed two Cre Tg mini-pig lines by using 3.0-kb and 8.0-kb pig $A Q P 2$ 5'-flanking region respectively.

To our surprise, these two Cre Tg mini-pig lines characterize with absolutely different Cre expression patterns. The Cre Tg mini-pigs with 8-kb AQP2 5 '-flanking region display an expected expression pattern of Cre within kidney collecting duct [21], while the 3-kb AQP2 promoter region directed Cre expression was unanticipated present in AECs of Cre Tg mini- 
pigs. Moreover, characterization of Cre expression revealed that this Cre Tg mini-pig line exhibits stable expression within the AECs in founders and the first generation.

The AQP2 5'-flanking region directed Cre expression in AECs has not previously been reported. We speculated that potential regulation pathway(s) might be present in the AECs involved in the unexpected expression of AQP2-Cre in Tg mini-pigs. We therefore performed second round in vitro expression analysis. In this regard, a human alveolar basal epithelial cell line, A549, and other four cell lines were used. As a result, only AQP2-Cre transfected LLC-PK1 cells expressing Cre recombinase, whereas the others did not. Analogously, previous studies revealed that a 3-kb human $A Q P 2$ promoter region can efficiently direct the expression of reporter gene in LLC-PK1 cells, but not in rat IMCD cells, UT-87, Hep G2, HT-29, or NIH/3T3 cells [38]. These in vitro studies including expression pattern analysis of endogenous $A Q P 2$ in mini-pigs indicated that intracellular pathway(s) of AECs cannot regulate the $A Q P 2$ or $\mathrm{AQP} 2$-Cre expression.

Unexpected or varied expression of Cre recombinase has often been observed in Cre $\mathrm{Tg}$ mouse lines. For example, in an effort to generate a retinal pigmented epithelium (RPE)specific Cre line, Ueki et al. used a $3.0 \mathrm{~kb}$ human vitelliform macular dystrophy-2 (VMD2) promoter to direct Cre expression, but they detected unanticipated Cre activity in the Müller cells during retinal development [39]. The Thy1-Cre Tg mouse line was initially created to express Cre recombinase in the postnatal cortex and hippocampal neurons [40]. Heffner et al. went on to demonstrate that it was also expressed in many additional tissues such as the myocardium, vascular endothelium, lung alveoli and bronchiole cells, renal tubules, skeletal muscle, skin, hair follicles, testis, and bladder [10]. These ectopic or varied cellular expression of Cre recombinase in the mouse and pig, suggest that unexpected expression of Cre recombinase is common in generating Tg Cre lines.

However, it is important to note that the most published studies focus on Cre expression in the tissues of interest, while ectopic or varied expression of Cre in other tissues are rarely reported. This means that a Cre line with varied expression is generally unavailable to potential users since the data were unreported. For example, the promoter fragment of the rat insulin gene was previously used to direct expression of a reporter gene in endothelial cells [41]. However, Gustafsson et.al reported that ectopic expression was observed in the adult rat brain [42]. Critically, the ectopic or varied expression of Cre may lead to the misinterpretation of phenotypes and could have a major impact on the final conclusions drawn from experiments $[43,44]$. Though the generated Cre Tg mini-pigs characterize with unexpected expression of Cre, the systematical investigation is considered to be essential for further studies.

In this study, all 12 founder Tg mini-pigs were generated from a single cell clone using pig SCNT. The Cre copy number and integration site analysis indicated that these Tg minipigs all had similar integration patterns. Previously, Kong et al. proposed that Tg animals generated using SCNT, when they are derived from a single donor colony, should have a single genotype [27]. Our observations support this proposition. Furthermore, as the Cre copies did not significantly decline over time in the different aged mini-pigs, these Tg minipigs offer an option for investigating Cre expression variation with aging. We found that the expression levels of Cre were similar at all ages evaluated.

Uneven transgene passage between generations is a common observation in Tg animals, and previous reports concluded that this may influence expression $[45,46]$. We did note a significant decrease in the number of Cre copies transmitted between founder (parent) and offspring, while Cre expression was stable. Notably, one integration site, ID.4, was absent from the genome of piglet No.2488; however, the Cre expression was readily detectable. This observation indicates that exogenous may be easily lost during fertilization, but expression can be maintained.

Although the AQP2-Cre mini-pig line exhibits exclusive and stable expression of Cre recombinase within the AECs, several fundamental questions remain unanswered. For instance, advanced testing of the AQP2-Cre Tg mini-pig lines for recombination efficiency and specificity will be necessary. Previous reports showed that the Cre-mediated recombination 
might vary between generations or genomic target locations [47-49]. Therefore, further studies demonstrating the efficiency of the Cre to promote floxed-specific recombination are required, which could be accomplished by mating the Cre Tg mini-pig with a "reporter" Tg mini-pig, notably the Tg mini-pigs containing pICE-STOP [30]. In addition, Tg animals may segregate the integration patterns when mated with non-Tg animals [50,51]. Although heterozygous Cre expression mouse lines have been used to generate conditional gene targeting mouse models [52-54], the sustained analysis of Cre integration patterns and expression in subsequent generations may be required for further applications of the AQP2Cre Tg mini-pigs. Furthermore, the identified integration sites were shown to be on distinct genome loci in this study. Notably, integration site ID3 was located within an intron of the transmembrane protein 163 (TMEM163) gene. In rodents, TMEM163, is expressed in a wide extension of the brain [55]. Previous reports showed that TMEM163 is predicted to form an integral membrane protein with six transmembrane helices and involved in cell growth and migration [56]. Whether the integrated AQP2-Cre plasmids influence TMEM163 expression needs to be further analyzed. All these factors must be taken into account when choosing a cre driver strain for conditional knockout experiments.

In this study, the AQP2-Cre Tg mini-pigs were generated by a random integration. The unexpected expression domain of Cre may be due to positional effects that can occur in $\mathrm{Tg}$ animals $[57,58]$. Therefore, we initially analyzed the genes located $50 \mathrm{~kb}$ up- and downstream of the insertion sites (Table 6). However, we found no potential promoters or TRBEs present in this region that may influence the expression of AQP2-Cre.

In addition to the position effect, several other hypotheses about the unique expression of transgene are possible. Firstly, we cannot exclude some complex mechanisms, such as long-distance regulation or interaction between exogenous and locus regulatory regions, that could lead to varied expression of transgene [59,60]. For example, mutations in a conserved non-coding region in intron 5 of the Lmbr1 locus, which is $1 \mathrm{Mb}$ away from the sonic hedgehog (Shh) coding sequence, caused a complete loss of Shh expression in the limb buds [61]. Previous studies also showed that the transgene can interact with locus control regions and thereby disrupt normal interactions between local and long-distance regulatory regions within a tissue-specific domain [62]. Additionally, comparing the Cre expression patterns of 8-kb and 3-kb $A Q P 2$ 5'-flanking region directed Cre driver lines, we suppose that the 3 -kb $A Q P 25$ '-flanking region may miss regulatory elements crucial in controlling the tissue-specific expression of Cre. It is also important to note that some regulation mechanisms, such as cAMP, NFATc, and NF-kappaB signal pathways, were found to be critical for $A Q P 2$ expression in vivo or in vitro $[38,63,64]$. Thus, a precise understanding of the regulation elements and molecular mechanisms of cell-specific expression of $A Q P 2$ awaits further studies. Moreover, DNA methylation plays an important role in altered expression of transgene $[65,66]$. Future studies will be needed to determine the methylation status of the $A Q P 2$ fragment used in this $\mathrm{Tg}$ mini-pig line.

Here, the mechanisms causing unexpected expression of transgene are poorly understood $[67,68]$. The exact reason for the unexpected expression domain of the AQP2Cre is beyond the focus of our study. Indeed, we successfully generated a lung-specific Cre expression mini-pig tool and the current study highlights several potentially issues that must be considered when designing specific Cre driver strains. This AQP2-Cre Tg mini-pig line showed no apparent defect, and the expression pattern of Cre recombinase was exclusive and stable between generations. Importantly, the coding sequence of Cre used in this study has been shown to be effective in previous studies. Thus, we predict that this Cre mini-pig line will be a valuable tool for investigating gene function in AECs.

\section{Acknowledgments}

The authors would like to thank Qingkai Guo, Jian Wang, Xue Chen, Peiran Hu and Yong Fang for technical assistance. We thank the members of the Animal Biotechnology laboratory, 
College of Animal Science, Jilin University, for their helpful discussions during the course of this work.

This work was supported by the National Natural Science Foundation of China (Grant No. 31201750), China National Key Basic Research Program [973 Program, No. 2011CB944200], and Program for Changjiang Scholars and Innovative Research Team and Innovative Research Team in University (PCSIPT, No. IRT1248)

\section{References}

1 Hoess R, Abremski K, Sternberg N: The nature of the interaction of the P1 recombinase Cre with the recombining site loxP. Cold Spring Harb Symp Quant Biol 1984;49:761-768.

-2 Karimova M, Abi-Ghanem J, Berger N, Surendranath V, Pisabarro MT, Buchholz F: Vika/vox, a novel efficient and specific Cre/loxP-like site-specific recombination system. Nucleic Acids Res 2013;41:e37.

3 Sauer B: Functional expression of the Cre-loxP site-specific recombination system in the yeast Saccharomyces cerevisiae. Mol Cell Biol 1987;7:2087-2096.

-4 Sauer B, Henderson N: Site-specific DNA recombination in mammalian cells by the Cre recombinase of bacteriophage P1. Proc Natl Acad Sci USA 1988;85:5166-5170.

5 Odell J, Caimi P, Sauer B, Russell S: Site-directed recombination in the genome of transgenic tobacco. Mol Gen Genet 1990;223:369-378.

6 Kühn R, Torres RM: Cre/loxP recombination system and gene targeting. Methods Mol Biol; 2002:175-204.

7 Okuyama T, Isoe Y, Hoki M, Suehiro Y, Yamagishi G, Naruse K, Kinoshita M, Kamei Y, Shimizu A, Kubo T: Controlled Cre/loxP site-specific recombination in the developing brain in medaka fish, Oryzias latipes. PloS One 2013;DOI: 10.1371/0079159.

8 Smedley D, Salimova E, Rosenthal N: Cre recombinase resources for conditional mouse mutagenesis. Methods 2011;53:411-416.

-9 Tahimic CG, Sakurai K, Aiba K, Nakatsuji N: Cre/loxP, FLP/FRT systems and pluripotent stem cell lines; Sitedirected insertion of transgenes, Springer, 2013, vol. 23, pp189-209.

10 Heffner CS, Pratt CH, Babiuk RP, Sharma Y, Rockwood SF, Donahue LR, Eppig JT, Murray SA: Supporting conditional mouse mutagenesis with a comprehensive Cre characterization resource. Nat Commun 2012;3:1218.

11 Gannon M, Shiota C, Postic C, Wright CV, Magnuson M: Analysis of the Cre-mediated recombination driven by rat insulin promoter in embryonic and adult mouse pancreas. Genesis 2000;26:139-142.

-12 Wicksteed B, Brissova M, Yan W, Opland DM, Plank JL, Reinert RB, Dickson LM, Tamarina NA, Philipson LH, Shostak A: Conditional gene targeting in mouse pancreatic beta-cells analysis of ectopic Cre transgene expression in the brain. Diabetes 2010;59:3090-3098.

13 Lee KY, Russell SJ, Ussar S, Boucher J, Vernochet C, Mori MA, Smyth G, Rourk M, Cederquist C, Rosen ED: Lessons on conditional gene targeting in mouse adipose tissue. Diabetes 2013;62:864-874.

14 Liu P, Jenkins NA, Copeland NG: Efficient Cre-loxP-induced mitotic recombination in mouse embryonic stem cells. Nat Genet 2001;30:66-72.

15 Schmidt-Supprian M, Rajewsky K: Vagaries of conditional gene targeting. Nat Immun 2007;8:665-668.

16 Soriano P: Generalized lacZ expression with the ROSA26 Cre reporter strain. Nat Genet 1999;21:70-71.

17 Tober J, Yzaguirre AD, Piwarzyk E, Speck NA: Distinct temporal requirements for Runx1 in hematopoietic progenitors and stem cells. Development 2013;140:3765-3776.

18 Fushimi K, Uchida S, Hara Y, Hirata Y, Marumo F, Sasaki S: Cloning and expression of apical membrane water channel of rat kidney collecting tubule. Nature 1993;361:549-552.

19 He R-H, Sheng J-Z, Luo Q, Jin F, Wang B, Qian Y-L, Zhou C-Y, Sheng X, Huang H-F: Aquaporin-2 expression in human endometrium correlates with serum ovarian steroid hormones. Life Sci 2006;79:423-429.

20 Rubera I, Hummler E, Beermann F: Transgenic mice and their impact on kidney research. Pflugers Arch 2009;458:211-222.

21 Luo W, Li Z, Huang Y, Han Y, Yao C, Duan X, Ouyang H, Li L: Generation of AQP2-Cre transgenic mini-pigs specifically expressing Cre recombinase in kidney collecting duct cells. Transgenic Res 2014;23:365-375.

-22 Fehrenbach H: Alveolar epithelial type II cell: defender of the alveolus revisited. Respir Res 2001;2:33-46.

23 Guillot L, Nathan N, Tabary O, Thouvenin G, Le Rouzic P, Corvol H, Amselem S, Clement A: Alveolar epithelial cells: master regulators of lung homeostasis. Int J Biochem Cell Biol 2013;45:2568-2573. 
24 Chen L, Li L, Pang D, Li Z, Wang T, Zhang M, Song N, Yan S, Lai L, Ouyang H: Construction of transgenic swine with induced expression of Cre recombinase. Animal 2010;4:767-771.

25 Lai L, Prather RS: Production of cloned pigs by using somatic cells as donors. Cloning Stem Cells 2003;5:233-241.

-26 Ingham DJ, Beer S, Money S, Hansen G: Quantitative real-time PCR assay for determining transgene copy number in transformed plants. Biotechniques 2001;31:132-141.

27 Kong Q, Wu M, Huan Y, Zhang L, Liu H, Bou G, Luo Y, Mu Y, Liu Z: Transgene expression is associated with copy number and cytomegalovirus promoter methylation in transgenic pigs. PloS One 2009; DOI:10.1371/0006679.

-28 Whyte JJ, Prather RS: Genetic modifications of pigs for medicine and agriculture. Mol Reprod Dev 2011;78:879-891.

29 Leuchs S, Saalfrank A, Merkl C, Flisikowska T, Edlinger M, Durkovic M, Rezaei N, Kurome M, Zakhartchenko V, Kessler B: Inactivation and inducible oncogenic mutation of p53 in gene targeted pigs. PloS One 2012;DOI:10.1371/ 0043323.

- 30 Li L, Pang D, Wang T, Li Z, Chen L, Zhang M, Song N, Nie D, Chen Z, Lai L: Production of a reporter transgenic pig for monitoring Cre recombinase activity. Biochem Biophys Res Commun 2009;382:232-235.

- 31 Li X, Yang Y, Bu L, Guo X, Tang C, Song J, Fan N, Zhao B, Ouyang Z, Liu Z: Rosa26-targeted swine models for stable gene over-expression and Cre-mediated lineage tracing. Cell Res 2014;24:501-504.

-32 Breton S, Alper SL, Gluck SL, Sly WS, Barker JE, Brown D: Depletion of intercalated cells from collecting ducts of carbonic anhydrase II-deficient (CAR2 null) mice. Am J Physiol 1995;269:F761-F774.

-33 Nielsen S, DiGiovanni SR, Christensen EI, Knepper MA, Harris HW: Cellular and subcellular immunolocalization of vasopressin-regulated water channel in rat kidney. Proc Natl Acad Sci USA 1993;90:11663-11667.

-34 Skowronski MT, Kwon T-H, Nielsen S: Immunolocalization of aquaporin 1, 5, and 9 in the female pig reproductive system. J Histochem Cytochem 2009;57:61-67.

35 Yu M-J, Miller RL, Uawithya P, Rinschen MM, Khositseth S, Braucht DW, Chou C-L, Pisitkun T, Nelson RD, Knepper MA: Systems-level analysis of cell-specific AQP2 gene expression in renal collecting duct. Proc Natl Acad Sci USA 2009;106:2441-2446.

-36 Guan Y, Hao C, Cha DR, Rao R, Lu W, Kohan DE, Magnuson MA, Redha R, Zhang Y, Breyer MD: Thiazolidinediones expand body fluid volume through PPARgamma stimulation of ENaC-mediated renal salt absorption. Nat Med 2005;11:861-866.

- 37 Zhang H, Zhang A, Kohan DE, Nelson RD, Gonzalez FJ, Yang T: Collecting duct-specific deletion of peroxisome proliferator-activated receptor gamma blocks thiazolidinedione-induced fluid retention. Proc Natl Acad Sci USA 2005;102:9406-9411.

- 38 Hozawa S, Holtzman EJ, Ausiello DA: cAMP motifs regulating transcription in the aquaporin 2 gene. Am J Physiol 1996;270:C1695-C1702.

-39 Ueki Y, Ash JD, Zhu M, Zheng L, Le Y-Z: Expression of Cre recombinase in retinal Müller cells. Vision Res 2009;49:615-621.

-40 Dewachter I, Reversé D, Caluwaerts N, Ris L, Kuipéri C, Van den Haute C, Spittaels K, Umans L, Serneels L, Thiry E: Neuronal deficiency of presenilin 1 inhibits amyloid plaque formation and corrects hippocampal long-term potentiation but not a cognitive defect of amyloid precursor protein [V717I] transgenic mice. J Neurosci 2002;22:3445-3453.

41 Korhonen J, Lahtinen I, Halmekyto M, Alhonen L, Janne J, Dumont D, Alitalo K: Endothelial-specific gene expression directed by the tie gene promoter in vivo. Blood 1995;86:1828-1835.

-42 Gustafsson E, Brakebusch C, Hietanen K, Fassler R: Tie-1-directed expression of Cre recombinase in endothelial cells of embryoid bodies and transgenic mice. J Cell Sci 2001;114:671-676.

43 Kucherlapati MH, Nguyen AA, Bronson RT, Kucherlapati RS: Inactivation of conditional Rb by Villin-Cre leads to aggressive tumors outside the gastrointestinal tract. Cancer Res 2006;66:3576-3583.

44 Rao T, Ranger JJ, Smith HW, Lam SH, Chodosh L, Muller WJ: Inducible and coupled expression of the polyomavirus middle $\mathrm{T}$ antigen and Cre recombinase in transgenic mice: an in vivo model for synthetic viability in mammary tumour progression. Breast Cancer Res 2014;DOI:10.1186/bcr3603.

45 Blewitt M, Whitelaw E: The use of mouse models to study epigenetics. Cold Spring Harbor Perspect Biol 2013;DOI:10.1101/a017939. 
-46 Le Y, Sauer B: Conditional gene knockout using Cre recombinase. Mol Biotechnol 2000;17:477-485.

47 Li H, Sung H-K, Qu D, Nagy A, Adamson SL: Conditional gene deletion in the placenta using the Cre-loxP system: The Guide to Investigation of Mouse Pregnancy, Academic Press, 2013, pp 309.

48 Nagy A: Cre recombinase: the universal reagent for genome tailoring. Genesis 2000;26:99-109.

-49 Erbs E, Pradhan AA, Matifas A, Kieffer BL, Massotte D: Evaluation of Cre recombinase delivery in mammalian cells using baculovirus infection. J Biotechnol 2013;166:182-186.

-50 Melo EO, Canavessi AM, Franco MM, Rumpf R: Animal transgenesis: state of the art and applications. J Appl Genet 2007;48:47-61.

-51 Pillai MM, Venkataraman GM, Kosak S, Torok-Storb B: Integration site analysis in transgenic mice by thermal asymmetric interlaced (TAIL)-PCR: segregating multiple-integrant founder lines and determining zygosity. Transgenic Res 2008;17:749-754.

52 Bouchard M, Souabni A, Busslinger M: Tissue-specific expression of Cre recombinase from the Pax8 locus. Genesis 2004;38:105-109.

53 Srinivas S, Watanabe T, Lin C-S, William CM, Tanabe Y, Jessell TM, Costantini F: Cre reporter strains produced by targeted insertion of EYFP and ECFP into the ROSA26 locus. BMC Dev Bio 2001;1:1-8.

54 Undeutsch H, Löf C, Offermanns S, Kero J: A mouse model with tamoxifen-inducible thyrocyte-specific Cre recombinase activity. Genesis 2014; 52:333-340.

-55 Montiel JF, Wang WZ, Oeschger FM, Hoerder-Suabedissen A, Tung WL, García-Moreno F, Holm IE, Villalón A, Molnar Z: Hypothesis on the dual origin of the Mammalian subplate. Front Neuroanat 2011;DOI: 10.3389/ 00025

-56 Shen Y, Chen C-S, Ichikawa H, Goldberg GS: SRC induces podoplanin expression to promote cell migration. J Biol Chem 2010;285:9649-9656.

-57 Amendola M, Giustacchini A, Gentner B, Naldini L: A double-switch vector system positively regulates transgene expression by endogenous microRNA expression (miR-ON vector). Mol Ther 2013;21:934-946. Jaenisch R: Transgenic animals. Science 1988;240:1468-1474.

-59 Ahn Y, Mullan HE, Krumlauf R: Long-range regulation by shared retinoic acid response elements modulates dynamic expression of posterior Hoxb genes in CNS development. Dev Biol 2014;388:134-144.

60 Bonifer C: Long-distance chromatin mechanisms controlling tissue-specific gene locus activation. Gene 1999;238:277-289.

61 Sagai T, Hosoya M, Mizushina Y, Tamura M, Shiroishi T: Elimination of a long-range cis-regulatory module causes complete loss of limb-specific Shh expression and truncation of the mouse limb. Development 2005;132:797-803.

62 Pham CT, Maclvor DM, Hug BA, Heusel JW, Ley TJ: Long-range disruption of gene expression by a selectable marker cassette. Proc Natl Acad Sci 1996;93:13090-13095.

-63 Albertoni Borghese M, Bettini LM, Nitta CH, de Frutos S, Majowicz M, Gonzalez Bosc L: Aquaporin-2 promoter is synergistically regulated by nitric oxide and nuclear factor of activated t cells. Nephron Extra 2011;1:124-138.

-64 Leroy V, De Seigneux S, Agassiz V, Hasler U, Rafestin-Oblin M, Vinciguerra M, Martin P, Féraille E: Aldosterona ativa o fator de transcrição nuclear nf-kappab: Aumenta proliferação celular e abole a apoptose no duto coletor: Teria o mesmo efeito no câncer? J Am Soc Nephrol 2009;20:131-144.

65 Choi K-H, Park J-K, Kim H-S, Uh K-J, Son D-C, Lee C-K: Epigenetic changes of lentiviral transgenes in porcine stem cells derived from embryonic origin. PloS One 2013;DOI: 10.1371/0072184.

66 Mehta AK, Majumdar SS, Alam P, Gulati N, Brahmachari V: Epigenetic regulation of cytomegalovirus major immediate-early promoter activity in transgenic mice. Gene 2009;428:20-24.

67 Chamling X, Seo S, Bugge K, Searby C, Guo DF, Drack AV, Rahmouni K, Sheffield VC: Ectopic expression of human BBS4 can rescue Bardet-Biedl syndrome phenotypes in Bbs4 null mice. PloS One 2013;DOI:10.1371/0059101.

68 Martin DI, Whitelaw E: The vagaries of variegating transgenes. Bioessays 1996;18:919-923. 